Small size or inconspicuousness achieved by various means enables some planktonic animals to evade fishes, and the possibility of doing so by vertical migration is also considered. Invertebrate predators can sometimes be thwarted by other means, as by protective spines or shapes that are difficult to handle, by escape reactions or simply by large size. Complexities arise when both types of predator are active: an anti-fish stratagem may increase vulnerability to a copepod. On the basis of case histories, somewhat subjective models are described which predict reactions to various kinds of predation and are shown to be in reasonable agreement with certain real life situations. Nature is, however, almost infinitely diverse and some categorical statements are incorrect. Thus Bosmina is not "dominant only when gape-limited predation is intense" - I know a score of fishless water-bodies where Bosmina dominates the open water, often alone - and it is nonsense to say that Daphnia magna (not truly planktonic) and D. pulex cannot co-exist. My records reveal $D$. pulex as the most frequent conspecific associate of $D$. magna.

And so to the factual errors, of which there are so many one hardly knows where to begin. The author does not know much about copepods or he would not refer to "large conspecifics" - adults do not moult - or ask "what function is served by their compound eyes?", organs they do not possess. Cyclopoids do not stab prey from behind with daggerlike mandibles. No mere quibble this: to understand protective devices we must know how the predator attacks. The statement that copepods "will attack neither very large nor very small prey" is also erroneous; cyclopoids that attack animals much larger than themselves, including small fishes, can be reared on protozoans. Considering its importance in the theories developed, size is indeed treated very carelessly. Some species of Ceriodaphnia attain more than twice the cited maximum size; the grotesque fullpage figure of Holopedium bears the wrong scale; and to suit a model three daphnids are lumped together "because they are within a range of $1.0 \mathrm{~mm}$ ", forgetting that in these small animals this reflects a difference of 125 per cent.

Other animals are equally abused. The full page figure that purports to be a Chaoborus larva (indexed as the phantom midget!) is only a head with part of the gut attached; the figure labelled Bythotrephes longimanus is Polyphemus pediculus; cladocerans not rotifers produce ephippia; stomatopods are not pistol shrimps nor notonectids water striders, and so one could go on. Carelessness, including a host of mis-spelled names, sometimes provides amusement - otter densities of 20 to 30 per $\mathrm{m}^{2}$ must be as remarkable a sight as fishes "feeding on the mollusc's feet".

Revised and re-written this could be a useful little book: as it stands it cannot be recommended.

Geoffrey Fryer is a Senior Principal Scientific officer at the Windermere Laboratory of the Freshwater Biological Association.

\title{
Physics and chemistry of membranes
}

\section{Ora Kedem}

\section{Basic Principles of Membrane Transport. By S.G. Schultz. Pp.204 Hbk ISBN 0-521-22992-8; pbk ISBN 0-521-29762-1. (Cambridge University Press: 1980.) Hbk $£ 14, \$ 22.50$; pbk £4.95, \$8.50.}

AlTHOUGH various treatises dealing with general aspects of membrane transport or membrane function are available, this book is a valuable addition to the literature. It is a unified presentation, starting from first principles and including discussions of some of the more important transport systems in the living organism. Nevertheless, it is appropriate that the title does not include any "bio-" key word because the author provides the physicochemical foundation for studying biological membranes, and does not attempt a summary of the detailed and rapidly growing physiological and biochemical information.

The structure of the book is logical and not historical; thus, for example, the GHK flux equation is thoroughly discussed in the chapter on isothermal diffusion, where it belongs. In the chapter on some principles of electrophysiology, the concept can then be applied in context. The brief summaries, at the end of some chapters, state any conclusions that one can draw from the relatively simple treatment and stress their limitations. Indeed, a feature of the book as a whole is that assumptions and argunients are clearly stated. While a formal quantitative account is given in enough detail to be readily followed by the reader, emphasis is on the physical significance of the results, and in many cases the physical meaning of steps in the derivation.

With this recommendation to both students and researchers in the field, a note of reservation is necessary. The desire for intuitively appealing explanation has led in some cases to inaccurate, or at least non-rigorous, statements. However, considering the logical development of the book as a whole - and the detailed references - these should not lead to any serious misunderstandings.

Ora Kedem is Professor in the Department of Membrane Research at The Weizmann Institute of Science, Rehovoth, Israel.
Isotopes and geology

\section{Gunter Faure}

Handbook of Environmental Isotope Geochemistry. Vol.1, The Terrestrial Environment, A. Edited by P. Fritz and J.Ch. Fontes. Pp.532. ISBN 0-444-41780X. (Elsevier Scientific: 1980.) Dfl.185, $\$ 90.25$.

THIS is the first of a proposed set of five volumes dealing with applications of isotopic studies to a wide variety of problems, ranging from the geochemistry of forest soil to igneous petrology. The first volume on the terrestrial environment gets off to a shaky start with a preface and an introduction by the series editors. They justify their ambitious undertaking with the claim that isotope geology reached its present importance in the earth sciences only in the context of geochemistry, hydrogeology and environmental geology. Applications of isotopic studies to dating of terrestrial (or extra-terrestrial?) materials and to palaeoclimatic studies are judged to be of limited practical importance; this point of view may explain why isotopic studies of interest "to economic and hardrock geologists" are relegated to the fifth volume. Yet, in spite of several factual errors, the introduction does contain much useful information on the systematics of isotope fractionation that may assist the reader in understanding technical details of the following twelve, more substantive, contributions.

The first five chapters are devoted to presentations of isotope fractionation in different terrestrial environments including the atmosphere, groundwater, ice and snow, and geothermal systems. These are followed by seven chapters dealing with more specific topics. All of the contributions were written by experts in their respective fields and contain a wealth of detailed information regarding isotopic and geochemical processes in different terrestrial environments. The articles by Deines on reduced carbon, Osmond on uranium disequilibrium in ground water, Savin on mineral-water interactions and Krouse on sulphur compounds in the environment are especially well organized and concisely written. Several others are a bit of a chore to read because they are long and discursive.

This book will be useful primarily to scientists in search of information about isotopic and geochemical studies when their own research impinges on the natural processes occurring on the Earth's surface. Each chapter is attended by a lengthy list of references that range over several decades from the early 1950 s up to and including 1978, and there are detailed author and subject indexes which enhance the value of the book as a source of information.

Gunter Faure is Professor of Geology at Ohio State University, Columbus, Ohio. 